\title{
Groups of the Body Constitution and Age-Related Anthropometric Parameters in Kyrgyz Women
}

\author{
Kyialbek Sakibaev', Dmitry Nikityuk ${ }^{2,3}$, Nazgul Tashmatova1, Mirlan Nuruev', \\ Lazokatkhan Dzhumaeva', Zhanibek Muratov, Svetlana Klochkova5, \\ Zhypargul Abdullaeva ${ }^{*}{ }^{(1)}$, Kadyr Kozuev ${ }^{1}$
}

\footnotetext{
${ }^{1}$ Department of Anatomy, Histology and Normal Physiology, International Medical Faculty, Osh State University, Osh, Kyrgyzstan ${ }^{2}$ Federal Research Centre of Nutrition and Biotechnology, Moscow, Russia

${ }^{3}$ Department of Operative Surgery and Topographical Anatomy, Moscow State Medical University Named after I.M. Sechenov, Moscow, Russia

${ }^{4}$ Department of Pathology, Basic and Clinical Pharmacology, International Medical Faculty, Osh State University, Osh, Kyrgyzstan ${ }^{5}$ Department of Human Anatomy, Peoples' Friendship University of Russia, Moscow, Russia
}

Email: *jypar.science@oshsu.kg

How to cite this paper: Sakibaev, K., Nikityuk, D., Tashmatova, N., Nuruev, M., Dzhumaeva, L., Muratov, Z., Klochkova, S., Abdullaeva, Z. and Kozuev, K. (2020) Groups of the Body Constitution and Age-Related Anthropometric Parameters in Kyrgyz Women. Forensic Medicine and Anatomy Research, 8, 65-80.

https://doi.org/10.4236/fmar.2020.84007

Received: August 27, 2020

Accepted: September 27, 2020

Published: September 30, 2020

Copyright $\odot 2020$ by author(s) and Scientific Research Publishing Inc. This work is licensed under the Creative Commons Attribution International License (CC BY 4.0).

http://creativecommons.org/licenses/by/4.0/

(c) (i) Open Access

\begin{abstract}
This article is investigating constitutional and age characteristics of the body length, body weight, body mass index (BMI), and the absolute fat mass of Kyrgyz women. The features of the BMI and fat body mass in females with different constitutional and age groups were studied. According to our study, the leptosomatic group of body constitution was determined in $20 \%$ of women, while the mesosomatic group noted in $32 \%$, megalosomatic group recorded in 33\%, and an indefinite group established in 15\% among the studied women. Stenoplastic constitution was $66 \%-77 \%$ in the leptosomal constitution; asthenic thin bone group was $18 \%-24 \%$; and broad bone group somatotypes were $5-10 \%$. The proportion of the mesoplastic group was 31 $66 \%$, which is greater than picnic somatotype $(34 \%-69 \%)$. Results of our study revealed constitutional and age peculiarities are important for prescriptions in practical medicine.
\end{abstract}

\section{Keywords}

Body Mass Index, Absolute Fat Mass, Age, Leptosomatic, Mesosomatic, Megalosomatic, Indefinite, Anthropometric Parameters

\section{Introduction}

A personalized approach to patients is one of the priorities in the development 
of modern medicine [1]. At the same time fundamental method for assessing the physical development, nutritional status, and determining the level of health in this approach, is the method of constitutional analysis (somatotype), which allows identifying the individual belonging to different somatotypes in a population analysis [2] [3] [4].

The heterogeneity of population is constitutionally anatomical, which is proved by numerous anthropometric studies [5] [6]. The constitutional predisposition of a person to the development of many somatic diseases is established, as well as the uneven effectiveness of treatment and their rehabilitation in representatives of different constitutional types [7] [8]. Therefore, the method of somatotypological (constitutional-anatomical) analysis deserves implementation in terms of practical applications for clinical practice.

Analysis of body mass index (BMI), which allows a personalized approach to assessing physical development and nutritional status for each patient [9] [10] is widespread, particularly in the clinic of internal diseases. The simplicity of the obtained data on the value of this index and its informative component makes possible to use it not only in large-scale epidemiological studies but also directly in the conditions of clinic and hospital [11] [12] [13]. The body mass index (BMI) is used for defining anthropometric height/weight characteristics in adults and for classifying or categorizing them into groups [14]. BMI of people with normal weight ranges from 18.5 to 24.9 ; BMI of overweight or grade I obesity people ranges from 25 to 29.9; BMI of people with grade II obesity ranges from 30 to 34.9; BMI of people with grade III obesity ranges from 35 to 39.9, and BMI of people with grade IV or morbid obesity is 40 or higher [15]. A BMI of less than 18.5 indicates chronic energy deficiency, while BMI more than 25 shows excess body weight, and more than 30 , demonstrates obesity. Nevertheless, BMI assessment without regard to the person's body constitution as well as the application of the same standard to different somatotypes is methodologically incorrect. For example, asthenic (thin and, small) or picnic somatotypes (constitutionally characterized by excessive fat deposition) should be considered differently [16] [17] [18].

Along with this, the standards of this indicator should take into account the constitutional characteristics of a person, gender characteristics, and nationality (ethnic characteristics) [19] [20].

The relevance of using the constitutional-typological approach in a comprehensive study of the human body is required by the demands of time. Somatotypes assessment was achieved by using standard methods, anthropometric instruments for calculations of triceps, skinfold thickness, biceps circumference, body weight and height [21]. Body constitution and anthropometric parameters undergo changes with age, type of occupation, and physical activities [22] [23] [24]. Anthropometric measurements for estimation of total body mass using an information-theoretic approach were reported [25]. According to the recent literature, there is a large amount of information about the dependence of the morphological and functional characteristics of individual human body organs 
and systems from the types of body physique and aging [26] [27] [28]. However, in practice, up to date, the features of individual anatomical variability, organs and systems are not always compared with the constitutional features of the subjects. Despite of a significant number of similar profiles works [29] [30], the somatotypological characteristics of various ethnic groups were not sufficiently presented in the scientific literature.

Modern materials on the physical status of Kyrgyz women presented in small quantities. Some works on the body mass index and absolute body constitution, which is an important aspect when considering the weight. There have been only a few studies about anthropometric features of ethnic Kyrgyz people of different age groups, but it included data about growth-weighted indexes of men of youthful and mature age and not comprised any considered information about women [31].

Therefore, a study of physical development and nutritional status specifics from the perspective of modern constitutional science seems to be the most important medical and social problem, since only $56.4 \%$ of men and $55.9 \%$ of women have normal body mass indicators; overweight observed in $34.6 \%$ of men and $30.2 \%$ of women with Kyrgyz nationality.

According to the data of the National Statistics Committee, 2015 of the Kyrgyz Republic more than half of men and women age 40 and older have overweight or obesity. Alimentary obesity is turning to an epidemiologic character in Kyrgyzstan [32] [33] [34]. At the present division of Kyrgyz women into various constitutional-anatomical somatotypes was not determined, there is the absence of appropriate qualitative norms and individual variations of body parameters in the normal conditions. The most liable and least dynamic parameters of the body physique and component composition of the body during the transition from one age group to another have not been determined [35].

Another study dedicated to the prevalence of childhood and adolescent overweight and obesity in Asian countries but this research has no information about the somatotype of the considered groups [36]. That is why we have initiated research including groups of the body constitution in Kyrgyz women. The objective of our work was to study the features of BMI and fat body mass in females of different constitutional and age groups.

\section{Materials and Methods}

All actual research materials collected in the period from 2009 to 2018. The complex of anatomical and anthropometric examinations (Figure 1) was following generally accepted ethical standards and approved by the local ethics committee of Medical Problems Institute in Southern Branch National Academy of Sciences of the Kyrgyz Republic (12.10.16, protocol No. 4). All subjects signed an Informed Consent Form to participate in anthropometric studies. Sampling is based on the principle of voluntary participation. Generally, the accepted traditional scheme of age-related periodization of ontogenesis applied in this study. Using the method 


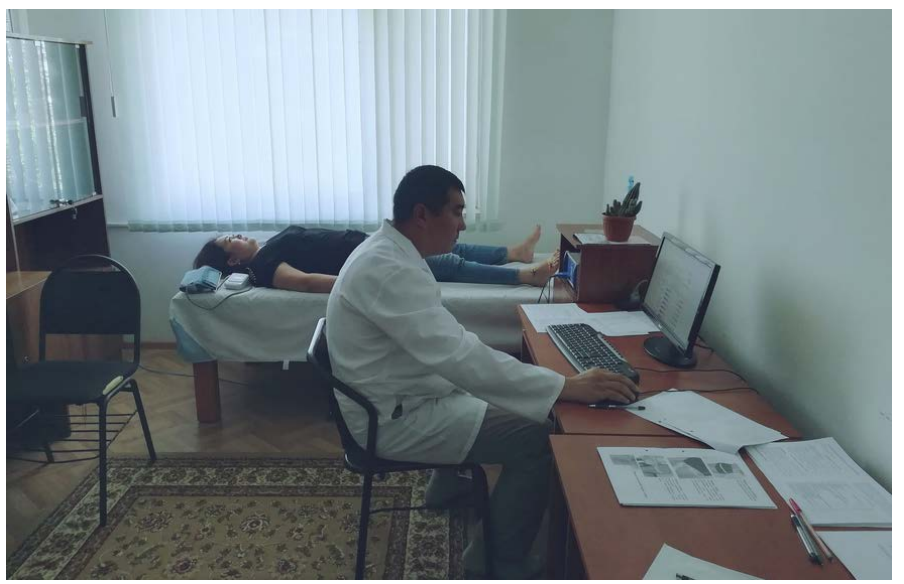

Figure 1. Anatomical and anthropometric examination.

of complex anthropometry and bioimpedancemetry ("Medass"), we have also studied the physical status of 1028 ethnic Kyrgyz women of various age groupsjuvenile (16 - 20 years old-310 maidens), adulthood I group (21 - 35 years old-308 women; adulthood II, 36 - 55 years old-410 women), living in Osh and its surroundings in Kyrgyzstan. The subjects did not include cases with diseases affecting physical status (alimentary-dependent pathology, degenerative-dystrophic diseases, etc.). The stature measured by a height meter. When measuring stature, the subjects stood with their backs to the vertical wall stand. The regulator lowered until it touched the head. The BMI was determined by dividing the body weight in grams by the body height in centimeters. Weight measured by using weights. Analysis of the body constitution carried out according to the scheme [37]. At the same time, three constitutional groups (categories) distinguished, within the framework of which seven somatotypes differentiated. The leptosomal constitution combined asthenic and stenoplastic types; mesosomal-picnic and mesoplastic; megalosomal constitution-athletic, sub-athletic, and euriplastic somatotypes. Within the euryplastic somatotype, short (body length less than 165 $\mathrm{cm}$ ) and tall (height is more than $165 \mathrm{~cm}$ ) variants were distinguished. Among women of asthenic somatotype, thin-boned and wide-boned distinguished. We have considered as appropriate to isolate indefinite somatotype during examination according to the complex of studied characters that did not correspond to any other somatotypes.

Morphometric processing of the results carried out on a computer using statistical programs Microsoft Excel and the STATISTICA package (v. 6.0). These results were presented as the arithmetic mean values (X), and their error (Sx), recorded the minimum (Min) and maximum (Max) individual variants of each parameter. Determination of significance and difference between indicators is achieved by using the Student criterion. Differences between two comparable measures were considered significant at $\mathrm{p}<0.05$.

\section{Results and Discussions}

Based on the anthropometry, distribution data of the studied female population 
under the membership of individuals in a particular constitutional group obtained which shown in Figure 2. According to the data presented, women of the leptosomal constitutional group identified in 208 cases, mesosomal group in 330, megalosomal group in 346, and indefinite group in 144 cases. Percentage representation in the population showed that the content of women of the leptosomal constitutional group (20\%) was 1.6 times less than the mesosomal group $(\mathrm{p}<$ $0.05)$, and 1.7 times less than megalosomal group $(\mathrm{p}<0.05)$, but more than representatives of the indefinite group (1.4 times, $\mathrm{p}<0.05$ ). Moreover, the individual minimum and maximum percentages in women of different constitutional groups with leptosomic somatotype are less than the meso- and megalosomal groups, but more than an indefinite constitutional group.

Representation analysis of women with different constitutional groups in adolescence, $1^{\text {st, }}$ and $2^{\text {nd }}$ periods of adulthood is shown in Figure 3 . The mesosomal constitutional group dominates in absolute values of the trait in adolescence (100

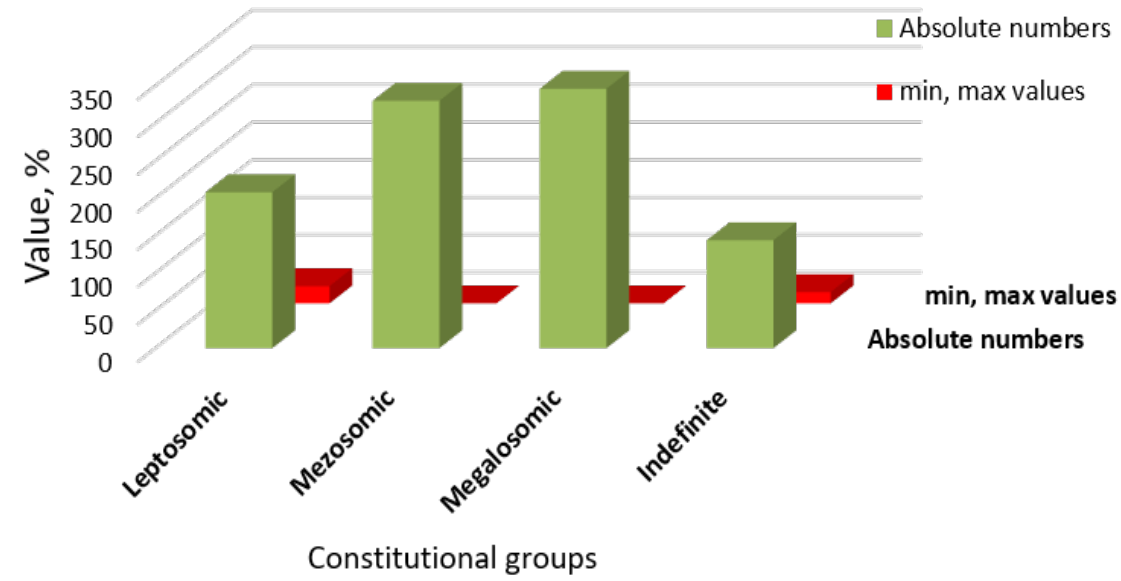

Figure 2. Distribution by constitutional groups of women of youth and adulthood (abs. value of the indicator and its value in percentage with min-max of this parameter).

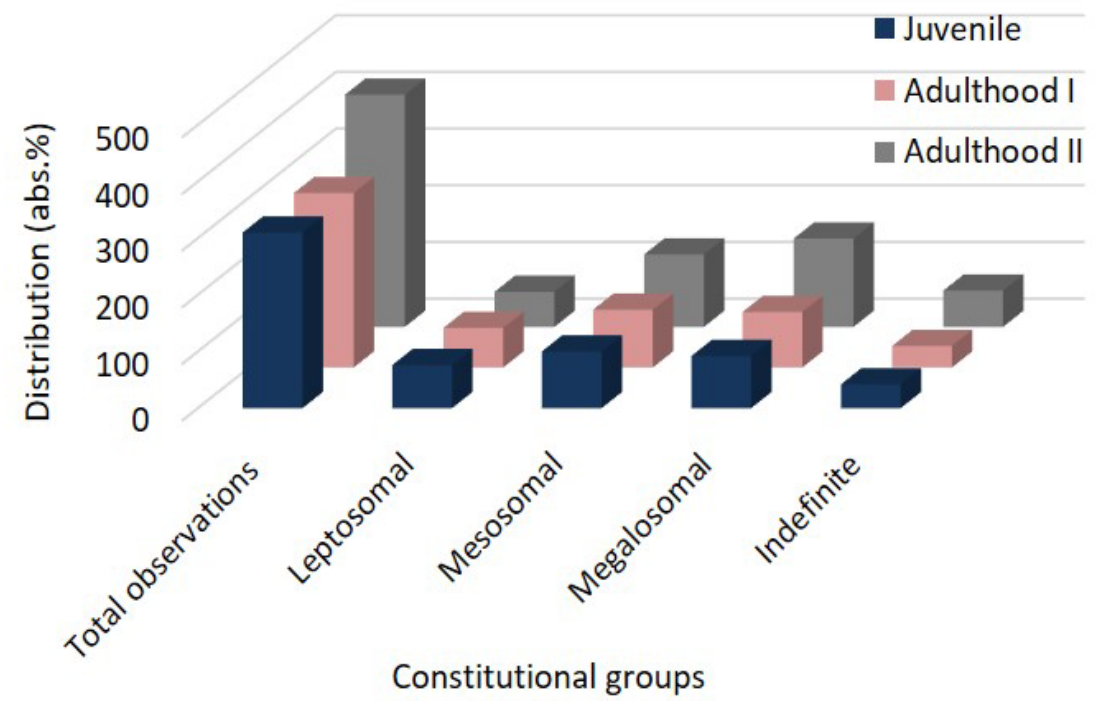

Figure 3. Distribution of women among constitutional groups according to age (abs. \%). 
cases), among the girls the megalosomal group is 92 , the leptosomal group is 76 , and 42 are identified in the indefinite constitutional group (102). Megalosomal group was 98, leptosomal was 70, and the uncertain group was in 38 cases. Among women of the adulthood II group the largest representation was noted in the megalosomal group (156 observations), 128 women belong to the mesosomal group, and approximately the same number of women belong to the leptosomal and indefinite groups (62 and 64).

Age-related features of different constitutional groups' representation in women and girls revealed proportion tendency in mesosomal and megalosomal groups. The relative number of women in adulthood I period of mesosomal and megalosomal groups were more significant, comparing to the leptosomal and undefined groups. Among women of the adulthood II age group, the megalosomal constitution was prevailed comparing to the mesosomal group, as well as for leptosomal and undefined constitutional groups. Representatives of mesosomal group observed 1.03 times more often compared to girls in the adulthood I period, in old age, they were 1.04 times less. The percentage of women in the megalosomal constitutional group was 1.1 times higher comparing to girls in adulthood I period and 1.3 times higher in the adulthood II period. The relative number of women in the indefinite group was 1.1 times less comparing to the girls of adulthood I period, and 1.2 times more in the adulthood II period. At the same time, during the transition from the juvenile period to adulthood, I period, and then to the adulthood II period, no fundamental changes in the constitutional features observed, which corresponds to the concept of B. A. Nikityuk and V. P. Chtetsov [37] on the modification nature of these changes.

Among women of the leptosome group representatives of the stenoplastic somatotype dominated, the minimum number of women in the asthenic wide-bone somatotype and the asthenic thin-bone somatotypes revealed (Table 1).

In relative values the number of women in stenoplastic somatotype was greater, comparing to asthenic wide-bone type 9.9 times $(\mathrm{p}<0.05)$, and asthenic thin-bone type was greater 3.4 times $(\mathrm{p}<0.05)$. Figure 4 is showing types of body constitutional groups in women.

The relative number of women's minimum and maximum values in stenoplastic type was significantly larger than asthenic wide-bone type and asthenic thin-bones types. Among women of the mesosomal group, representatives of the mesoplastic somatotype prevailed in absolute terms; the number of women with a picnic somatotype was less. In percentage, the former is represented by 1.1 times more than representatives of the picnic somatotype $(p<0.05)$. The personal minimum and maximum percentages of women of the picnic type were slightly larger than in the mesoplastic constitutional type. We used a generally accepted traditional scheme of age-related periodization of ontogenesis as shown in Figure 5.

The body length and weight, and, accordingly, the BMI significantly depend on the type of body constitution (Table 2). 
Table 1. Somatotypological groups of women belonging to different constitutions (absolute value of the indicator; value in \%).

\begin{tabular}{ccc}
\hline Constitution and somatotype & Number of observations & Value of parameter, \% \\
\hline Leptosomic group & 208 & 7 \\
Asthenic wide boned & 15 & 21 \\
Asthenic thin boned & 44 & 72 \\
Stenoplastic & 149 & \\
Mesosomal type & $330:$ & 47 \\
Picnic type & 155 & 53 \\
Mesoplastic type & 175 & \\
Megalosomal group & 346 & 12 \\
Athletic & 8 & 10 \\
Sub-athletic & 35 & 29 \\
Euriplastic tall & 101 & 59 \\
Euriplastic short & 202 & $100 \%$ \\
Indefinite group & 144 & \\
\hline
\end{tabular}

Table 2. Weight-for-height and the BMI in the juvenile, adulthood I, and adulthood II periods in females of different constitutional groups $(\mathrm{X}+\mathrm{Sx}$; min-max).

\begin{tabular}{|c|c|c|c|c|}
\hline \multirow{2}{*}{$\begin{array}{l}\text { Women age period } \\
\text { Leptosomic group }\end{array}$} & \multicolumn{4}{|c|}{ Constitutional groups } \\
\hline & Leptosomatic & Mesosomatic & Megalosomatic & Indefinite \\
\hline \multirow{3}{*}{ Juvenile } & \multicolumn{4}{|c|}{ Body length (cm) } \\
\hline & $158.5 \pm 0.6$ & $161.7 \pm 0.5$ & $167.1 \pm 0.6$ & $173.5 \pm 0.5$ \\
\hline & $142.0-166.2$ & $149.0-165.9$ & $154.8-189.0$ & $160.3-175.9$ \\
\hline \multirow{2}{*}{ Adulthood I } & $161.9 \pm 0.6$ & $161.9 \pm 0.3$ & $168.5 \pm 0.6$ & $167.5 \pm 0.5$ \\
\hline & $142.7-165.8$ & $154.5-165.4$ & $156.4-190.5$ & $156.3-170.9$ \\
\hline \multirow{2}{*}{ Adulthood II } & $154.6 \pm 0.5$ & $160.3 \pm 0.3$ & $165.4 \pm 0.9$ & $167.9 \pm 0.4$ \\
\hline & $143.2-164.5$ & $152.1-166.3$ & $154.2-192.4$ & $156.5-172.5$ \\
\hline & \multicolumn{4}{|c|}{ Bodyweight (kg) } \\
\hline \multirow{2}{*}{ Juvenile } & $44.5 \pm 0.5$ & $56.4 \pm 0.4$ & $70.9 \pm 0.6$ & $71.6 \pm 0.6$ \\
\hline & $36.4-54.5$ & $42.6-64.9$ & $56.4-92.3$ & $56.5-70.2$ \\
\hline \multirow{2}{*}{ Adulthood I } & $45.2 \pm 0.5$ & $68.4 \pm 0.4$ & $77.5 \pm 0.6$ & $72.3 \pm 0.6$ \\
\hline & $39.9-56.5$ & $54.3-82.3$ & $62.3-98.6$ & $60.4-75.1$ \\
\hline \multirow{3}{*}{ Adulthood II } & $46.2 \pm 0.4$ & $74.0 \pm 0.6$ & $85.1 \pm 0.6$ & $86.0 \pm 0.6$ \\
\hline & $39.9-57.4$ & $55.3-84.4$ & $68.4-99.6$ & $68.0-94.2$ \\
\hline & \multicolumn{4}{|c|}{ Body mass index (BMI) } \\
\hline \multirow{2}{*}{ Juvenile } & $17.1 \pm 0.2$ & $21.5 \pm 0.3$ & $25.3 \pm 0.2$ & $23.8 \pm 0.3$ \\
\hline & $12.2-24.5$ & $14.2-28.1$ & $20.2-30.4$ & $18.2-27.4$ \\
\hline \multirow{2}{*}{ Adulthood I } & $17.6 \pm 0.3$ & $26.2 \pm 0.2$ & $24.9 \pm 0.2$ & $25.8 \pm 0.3$ \\
\hline & $15.2-24.4$ & $20.2-29.5$ & $20.7-30.8$ & $21.4-31.4$ \\
\hline \multirow{2}{*}{ Adulthood II } & $18.7 \pm 0.3$ & $28.8 \pm 0.2$ & $31.2 \pm 0.2$ & $30.5 \pm 0.2$ \\
\hline & $16.8-24.5$ & $23.4-32.4$ & $24.3-38.1$ & $23.2-33.4$ \\
\hline
\end{tabular}


(1)

(a)

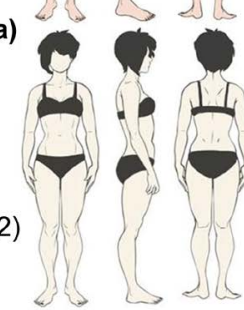

(1)

(b)

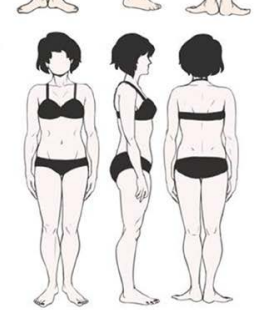

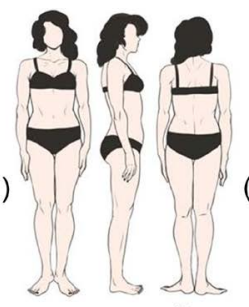

(c)

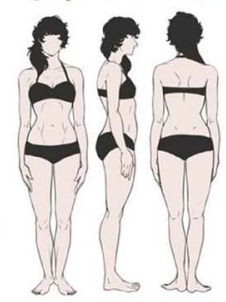

(3)

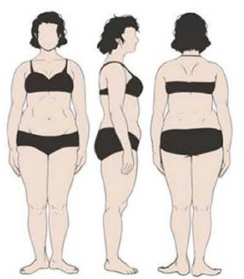

Figure 4. (a) Leptosomatic group of constitutions of women: (1) asthenic somatotype; (2) stenoplastic somatotype; (b) mesosomatic group: (1) picnic somatotype; (2) mesoplastic somatotype; (c) megalosomatic group: (1) athletic somatotype; (2) subathletic somatotype; (3) euryplastic tall somatotype; (4) euryplastic short somatotype.

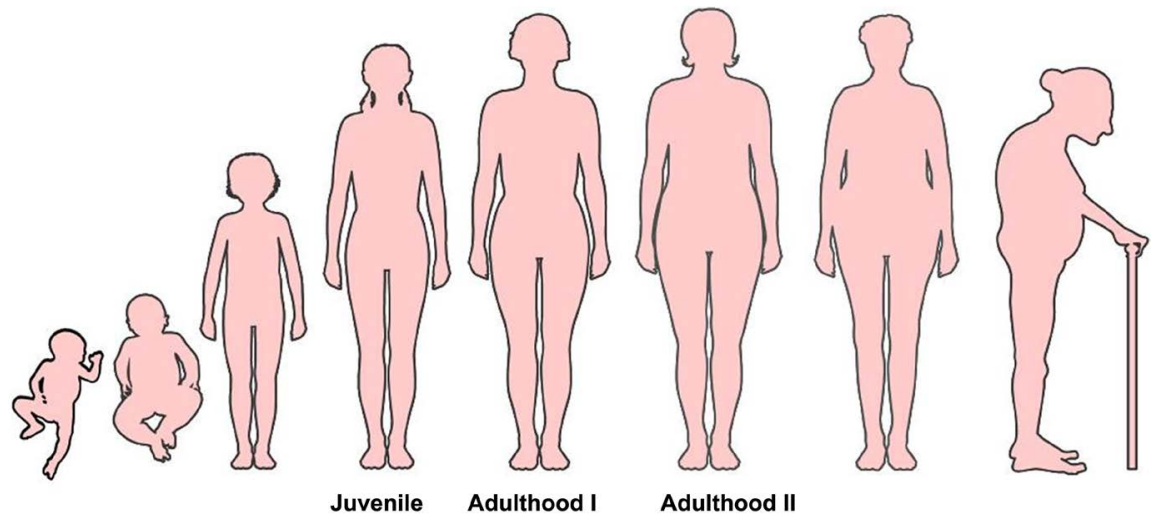

Figure 5. Age-related periodization of ontogenesis in women.

\subsection{Body Length}

In females of the leptosomatic group in adulthood period, the body length was the same as that of the mesosomatic group which is, less than in the megalosomatic and indefinite constitutional groups $(1.1$ times; $\mathrm{p}<0.05)$. The minimum and maximum body lengths in women with leptosomatic body constitution of considered age were slightly less than in women of megalosomatic and indefinite constitutional groups. Results obtained after analysis of growth-weight indicators (length, body weight, BMI) in girls and women of adulthood age with different somatotypes showed that the body length in girls was same with mesoplastic and euriplastic undersized and picnic somatotypes comparing to the asthenic thin-boned and wide-boned somatotypes. In girls of the athletic somatotype body length was 1.1 times more $(\mathrm{p}<0.05)$, in sub-athletic type, was 1.1 times more $(\mathrm{p}<0.05)$, in euriplastic tall type, was 1.1 times more $(\mathrm{p}<0.05)$ and in indefinite somatotype was 1.1 times more $(\mathrm{p}<0.05)$.

In women of the adulthood, I period the body length was stable and corres- 
ponded to asthenic group parameters. In athletic and sub-athletic somatotypes, the body length was 1.1 times greater $(\mathrm{p}<0.05)$, while in euriplastic tall and indefinite types was 1.1 times more $(\mathrm{p}<0.05)$. In the adulthood II period, the body length in women with stenoplastic and mesoplastic types corresponded to asthenic type; in picnic, athletic, and sub-athletic somatotypes the body length was 1.1 times more $(\mathrm{p}<0.05)$, in euryplastic short type no changes were observed; in euryplastic tall type and undefined group the body length was 1.1 times more ( $\mathrm{p}$ $<0.05)$. Women the minimum and maximum individual values of body length parameters were less in the asthenic somatotype comparing to the athletic, subathletic, and euriplastic tall somatotypes; in other somatotypes, these indicators showed an intermediate value.

We also revealed tendency according to which the body length slightly increases and then decreases during the transition from juvenile period to adulthood I period. An age-related decrease of the body length in the adulthood II period was probably associated with a flattening of the arches in foot, a decrease in thickness of intervertebral discs, and an increase in the sagittal curvature of the spine proved by anatomical facts [38].

\subsection{Body Weight}

In leptosomatic juvenile period, the body weight was less than in mesosomatic (1.3 times; $\mathrm{p}<0.05)$, megalosomatic, and indefinite constitutional groups (1.6 times; $\mathrm{p}<0.05)$. In adulthood, I, the body weight in women of the leptosomatic group was less than in the mesosomatic (1.5 times; $p<0.05)$, megalosomatic $(1.7$ times; $\mathrm{p}<0.05)$, and indefinite groups $(1.6$ times; $\mathrm{p}<0.05)$. In the adulthood II, the body weight in the women of the leptosomatic group compared with the women of the mesosomatic group, was less by 1.6 times $(\mathrm{p}<0.05)$ whereas it was less by 1.8 times in the megalosomatic group $(\mathrm{p}<0.05)$, and by 1.9 times in the indefinite group $(\mathrm{p}<0.05)$. Minimum and maximum body weights in leptosomatic women of age groups considered by us were less than in megalosomatic and indefinite groups. In stenoplastic type it is 1.3 times more $(\mathrm{p}<0.05)$, and in the mesoplastic one 1.4 times more $(\mathrm{p}<0.05)$, in picnic type was 1.5 times more $(\mathrm{p}<0.05)$, in athletic was 1.7 times more $(\mathrm{p}<0.05)$, in sub-athletic type was 1.7 times more $(\mathrm{p}<0.05)$, in euriplastic short type was 1.8 times more $(\mathrm{p}<0.05)$, in euriplastic tall type was 1.9 times more $(\mathrm{p}<0.05)$ and in indefinite somatotype was 1.8 times more $(\mathrm{p}<0.05)$.

The body weight in women of the adulthood I period does not change comparing to asthenic thin-boned somatotype. In asthenic wide-boned somatotype, and in stenoplastic type the body weight was 1.2 times more $(\mathrm{p}<0.05)$, in mesoplastic was 1.6 times more $(\mathrm{p}<0.05)$, in picnic type was 1.6 times more $(\mathrm{p}<$ $0.05)$, in athletic type was 1.6 times more $(\mathrm{p}<0.05)$, in sub-athletic type was 1.6 times more $(\mathrm{p}<0.05)$, in euriplastic short type was 2.0 times more $(\mathrm{p}<0.05)$, in euriplastic tall type was 2.1 times more $(p<0.05)$ and in indefinite somatotype was 1.7 times more $(\mathrm{p}<0.05)$. 
The body weight parameters in women of the adulthood II period were no changed comparing to asthenic thin-boned and wide-boned somatotypes. In stenoplastic type the body weights was 1.2 times more $(\mathrm{p}<0.05)$, in mesoplastic type was 1.7 times more $(\mathrm{p}<0.05)$, in picnic type was 1.8 times more $(\mathrm{p}<0.05)$, in athletic type was 1.7 times more $(\mathrm{p}<0.05)$, in sub-athletic type was 1.8 times more ( $\mathrm{p}<0,05)$, in the euriplastic short type was 2.1 times more $(\mathrm{p}<0.05)$, in euriplastic tall type was 2.3 times more $(p<0.05)$ and in indefinite somatotype was 2.0 times more $(\mathrm{p}<0.05)$.

\subsection{Body Mass Index (BMI)}

The standard value of BMI also depends on the body constitution (Table 2). BMI in the leptosomatic females in the juvenile period was less than that in the mesosomatic (1.2 times; $\mathrm{p}<0.05)$, megalosomatic $(1.5$ times; $\mathrm{p}<0.05)$, and indefinite $(1.4$ times; $\mathrm{p}<0.05$ ) groups. In the adulthood, I, the BMI in the women of the leptosomatic group was less than that in the mesosomatic (1.5 times; $\mathrm{p}<$ $0.05)$, in megalosomatic type 1.4 times less $(\mathrm{p}<0.05)$, and in indefinite type 1.5 times less $(\mathrm{p}<0.05)$. In adulthood II, the BMI in women of the leptosomatic group compared with the women of the mesosomatic group, was less by 1.6 times $(\mathrm{p}<0.05)$ whereas it was less by 1.7 times in the megalosomatic and indefinite groups $(\mathrm{p}<0.05)$. BMI and body weight, regardless of the constitutional group, increase by adulthood II, which should considered when assessing standards. The minimum and maximum values of BMI in leptosomatic women of all examined age groups were less than other body constitutions. BMI parameters are compared in the asthenic thin-boned and wide-boned somatotypes in girls (Table 3). As it is seen, BMI was 1.3 times greater in stenoplastic somatotype ( $p<$ $0.05)$, and 1.4 times greater in mesoplastic and picnic types $(\mathrm{p}<0.05)$, in the athletic and sub-athletic, indefinite types it was more 1.5 times $(\mathrm{p}<0.05)$, in the low-growth euryplastic type BMI was 1.9 times more $(\mathrm{p}<0.05)$, in a tall-euryplastic type, was 1.7 times more $(\mathrm{p}<0.05)$.

In women of the leptosomatic group of the adulthood I, the absolute fat mass was 2.3 times less than that in women of the mesosomatic group $(\mathrm{p}<0.05)$, while in megalosomatic and indefinite constitutions, it was less by $3.3(\mathrm{p}<0.05)$ and $2.4(\mathrm{p}<0.05)$ times, respectively. In women of the leptosomatic constitution in the adulthood II, the absolute fat mass was 2.2 times $(\mathrm{p}<0.05)$ less than that in women of the mesosomatic, while in the megalosomatic and indefinite constitutions, it was less by $3.6(\mathrm{p}<0.05), 2.7(\mathrm{p}<0.05)$ times. We have analyzed the features of absolute fat mass in the age aspect. The absolute value of the index in the leptosomatic women of adulthood I have not changed compared with the juvenile period, whereas in adulthood II, it has increased by 1.1 times $(\mathrm{p}<0.05)$. The absolute fat mass in females of the mesosomatic constitution in adulthood I, was 1.1 times higher $(\mathrm{p}<0.05)$ than it was in the juvenile period, while it was 1.2 times $(\mathrm{p}<0.05)$ higher in adulthood II. The absolute fat mass in women of the megalosomatic body constitution in adulthood I and II, was 1.1 and $1.3(\mathrm{p}<0.05)$ 
Table 3. Body length, body weight, and BMI values of women with different somatotypes $(X+S x$; min-max). Somatotype values in women of juvenile (1), adulthood I (2) and adulthood II (3) age groups.

\begin{tabular}{|c|c|c|c|}
\hline $\begin{array}{l}\text { Value, } \\
\text { age group }\end{array}$ & $\begin{array}{c}\text { Body length, cm } \\
1,2,3\end{array}$ & $\begin{array}{c}\text { Body weight, } \mathrm{kg} \\
1,2,3\end{array}$ & $\begin{array}{c}\text { BMI } \\
1,2,3\end{array}$ \\
\hline \multirow{6}{*}{$\begin{array}{l}\text { Asthenic } \\
\text { thin-boned }\end{array}$} & $160.1 \pm 1.4$ & $40.0 \pm 0.9$ & $15.6 \pm 0.2$ \\
\hline & $142.1-164.6$ & $36.0-50.0$ & $12.0-16.9$ \\
\hline & $160.3 \pm 2.4$ & $42.3 \pm 0.8$ & $16.5 \pm 0.3$ \\
\hline & $142.5-166.4$ & $39.7-47.2$ & $14.1-18.4$ \\
\hline & $156.2 \pm 1.63$ & $43.2 \pm 0.6$ & $17.7 \pm 0.2$ \\
\hline & $143.7-164.5$ & $39.9-48.1$ & $15.1-19.0$ \\
\hline \multirow{6}{*}{$\begin{array}{c}\text { Asthenic } \\
\text { wide-boned }\end{array}$} & $160.1 \pm 2.5$ & $41.2 \pm 1.8$ & $16.1 \pm 0.7$ \\
\hline & $145.7-164.0$ & $38.3-51.0$ & $12.3-17.9$ \\
\hline & $160.2 \pm 3.6$ & $44.2 \pm 2.0$ & $16.0 \pm 1.0$ \\
\hline & $145.6-165.1$ & $40.1-48.1$ & $15.3-19.2$ \\
\hline & $156.3 \pm 4.0$ & $45.5 \pm 2.6$ & $18.7 \pm 1.7$ \\
\hline & $144.1-162.5$ & $41.2-52.0$ & $16.0-20.0$ \\
\hline \multirow{6}{*}{ Stenoplastic } & $158.3 \pm 0.5$ & $51.7 \pm 0.3$ & $20.6 \pm 0.3$ \\
\hline & $147.3-164.0$ & $42.5-57.2$ & $14.0-24.1$ \\
\hline & $161.9 \pm 0.3$ & $49.1 \pm 0.2$ & $18.8 \pm 0.2$ \\
\hline & $152.2-165.3$ & $48.2-56.3$ & $16.4-23.5$ \\
\hline & $157.0 \pm 0.7$ & $49.9 \pm 0.5$ & $19.5 \pm 0.2$ \\
\hline & $145.2-163.1$ & $44.6-57.1$ & $18.1-24.6$ \\
\hline \multirow{6}{*}{ Mesoplastic } & $159.6 \pm 0.4$ & $54.2 \pm 0.7$ & $21.3 \pm 0.3$ \\
\hline & $149.1-165.0$ & $42.0-64.9$ & $15.1-27.1$ \\
\hline & $159.8 \pm 0.2$ & $68.2 \pm 0.3$ & $26.8 \pm 0.2$ \\
\hline & $153.1-163.1$ & $54.2-66.1$ & $22.1-29.0$ \\
\hline & $157.2 \pm 0.5$ & $72.0 \pm 1.0$ & $29.2 \pm 0.3$ \\
\hline & $149.8-166.1$ & $55.2-79.2$ & $24.2-32.6$ \\
\hline \multirow{6}{*}{ Picnic } & $163.6 \pm 0.7$ & $58.6 \pm 0.9$ & $21.9 \pm 0.1$ \\
\hline & $150.1-165.0$ & $64.4-82.4$ & $20.0-26.4$ \\
\hline & $163.8 \pm 0.8$ & $68.6 \pm 0.5$ & $25.6 \pm 0.1$ \\
\hline & $160.1-164.0$ & $65.1-82.3$ & $24.1-27.5$ \\
\hline & $163.2 \pm 0.3$ & $76.0 \pm 0.6$ & $28.6 \pm 0.2$ \\
\hline & $154.3-164.0$ & $69.1-84.0$ & $24.2-32.5$ \\
\hline \multirow{6}{*}{ Athletic } & $169.4 \pm 3.2$ & $66.2 \pm 3.2$ & $23.1 \pm 0.8$ \\
\hline & $165-192.1$ & $56.0-76.4$ & $22.0-25.0$ \\
\hline & $169.4 \pm 0.7$ & $68.2 \pm 0.5$ & $23.8 \pm 1.1$ \\
\hline & $162-169.8$ & $67.8-68.5$ & $20.0-25.4$ \\
\hline & $167.2 \pm 0.7$ & $75.0 \pm 1.8$ & $26.8 \pm 1.2$ \\
\hline & $162-177.2$ & $74.1-76.1$ & $22.0-28.0$ \\
\hline
\end{tabular}




\section{Continued}

\begin{tabular}{|c|c|c|c|}
\hline \multirow{6}{*}{ Sub-athletic } & $168.5 \pm 1.4$ & $68.2 \pm 0.8$ & $24.0 \pm 0.4$ \\
\hline & $165.4-187.0$ & $64.1-76.3$ & $20.1-26.1$ \\
\hline & $169.4 \pm 2.0$ & $69.3 \pm 1.29$ & $24.2 \pm 0.5$ \\
\hline & $161-178.3$ & $62.0-74.7$ & $20.3-26.2$ \\
\hline & $168.2 \pm 2.4$ & $76.2 \pm 3.6$ & $26.9 \pm 1.1$ \\
\hline & $154.8-177.2$ & $69.2-93.0$ & $21.0-28.4$ \\
\hline \multirow{6}{*}{ Euriplastic short } & $160.0 \pm 0.3$ & $73.6 \pm 0.6$ & $28.8 \pm 0.4$ \\
\hline & $154.8-164.8$ & $65.1-88.1$ & $21.3-31.2$ \\
\hline & $162.2 \pm 0.2$ & $82.9 \pm 0.6$ & $31.5 \pm 0.2$ \\
\hline & $156.0-164.1$ & $76.0-96.2$ & $22.5-34.0$ \\
\hline & $159.1 \pm 0.3$ & $90.0 \pm 0.4$ & $35.6 \pm 0.3$ \\
\hline & $154.0-164.7$ & $79.1-95.6$ & $25.9-38.3$ \\
\hline \multirow{6}{*}{ Euriplastic tall } & $170.1 \pm 0.7$ & $75.2 \pm 1.3$ & $26.0 \pm 0.4$ \\
\hline & $165.2-191.2$ & $68.3-92.5$ & $21.3-31.6$ \\
\hline & $172.6 \pm 0.70$ & $89.6 \pm 0.8$ & $29.9 \pm 0.2$ \\
\hline & $165.8-190.1$ & $80.2-98.1$ & $24.1-33.1$ \\
\hline & $167.1 \pm 0.7$ & $98.8 \pm 0.4$ & $35.4 \pm 0.3$ \\
\hline & $165.8-192.6$ & $88.5-99.5$ & $28.2-38.0$ \\
\hline \multirow{6}{*}{ Indefinite } & $173.5 \pm 0.7$ & $71.7 \pm 0.5$ & $23.9 \pm 0.2$ \\
\hline & $159-175.9$ & $56.3-74.0$ & $18.0-26.6$ \\
\hline & $167.4 \pm 0.6$ & $72.1 \pm 0.5$ & $25.8 \pm 0.4$ \\
\hline & $158-171.0$ & $60.3-75.6$ & $21.0-31.0$ \\
\hline & $167.9 \pm 0.7$ & $86.0 \pm 0.9$ & $30.5 \pm 0.3$ \\
\hline & $156.2-172.1$ & $68.0-94.2$ & $25.1-33.1$ \\
\hline
\end{tabular}

times higher $(\mathrm{p}>0.05)$ than it was in the juvenile period, respectively. The absolute fat mass in women of the indefinite body constitution in adulthood I and II was 1.2 and $1.5(p<0.05)$ times higher $(\mathrm{p}<0.05)$ than it was in the juvenile period, respectively. The minimum and maximum values of the absolute fat mass and its percentage in women of the adulthood II period with different body constitutions were more than in the juvenile period.

BMI in women of the adulthood I period compared with asthenic thin-boned somatotype, and does not change with its wide-boned somatotype. BMI was 1.1 times more in a stenoplastic somatotype $(\mathrm{p}<0.05)$, in mesoplastic somatotype was more to 1.6 times $(\mathrm{p}<0.05)$, in the picnic somatotype it was 1.6 times more ( $\mathrm{p}<0.05)$, in athletic type, was 1.4 times more $(\mathrm{p}<0.05)$, in sub-athletic type, was 1.5 times more $(\mathrm{p}<0.05)$, in euriplastic short type, was 1.9 times more $(\mathrm{p}<$ $0.05)$, in euriplastic tall type, was 1.8 times more $(\mathrm{p}<0.05)$ and in the undefined group was 1.6 times $(\mathrm{p}<0.05)$ more.

BMI in the adulthood II period was compared with asthenic thin-boned somatotype was 1.1 times greater $(p<0.05)$, in the wide-bonded type stenoplastic 
somatotype, was more 1.1 times $(\mathrm{p}<0.05)$, in mesoplastic type, was more 1.6 times $(\mathrm{p}<0.05)$, in the picnic somatotype, was more 1.6 times $(\mathrm{p}<0.05)$, athletic and sub-athletic groups was 1.5 times more $(\mathrm{p}<0.05)$, in the euryplastic short and tall types BMI was 2.0 times more $(\mathrm{p}<0.05)$ and in the indefinite group was 1.7 times more $(\mathrm{p}<0.05)$ more. Extreme individual BMI values for asthenic and stenoplastic somatotypes were less than in the juvenile and adulthood groups.

\subsection{Absolute Fat Mass}

The absolute fat mass is also unequal in women of different constitutional groups. Considering absolute fat mass in the juvenile period of the leptosomatic body constitution, it is content in the juvenile period of the mesosomatic and indefinite body constitutions prevail by 2.1 times $(\mathrm{p}<0.05)$, whereas in the megalosomatic body constitution it was more to 3.2 times $(\mathrm{p}<0.05)$.

\section{Conclusion}

In this article, we aimed to study the features of BMI and fat body mass in females of different constitutional and age groups. As a result of our study, constitutional and age peculiarities of body length, body weight, body mass index, and the absolute fat mass were revealed; the knowledge of which is important in practical medicine. Obtained results can be applied in developing measures for the timely detection of overweight and obesity as well as for the implementation of measures to prevent alimentary-related diseases in juvenile and adulthood periods. Somatometric assessments of the physical development can be used in dynamic monitoring of health status in organized groups: in educational institutions, youth sports schools, and in enterprises. Assessments of individual-typological features of individual physical development can be used in the development of regional biomedical programs aimed to strengthen and preserve the health issues of the younger generation. Presented materials on the physical development and constitutional-typological features of the studied female population under conditions of relative norms can be used in a personalized approach implementation of preventive and therapeutic-diagnostic measures in practical public health.

\section{Conflicts of Interest}

The authors declare no conflicts of interest regarding the publication of this paper.

\section{References}

[1] Bodiroga-Vukobrat, N., Rukavina, D., Pavelić, K. and Sander, G.G. (2019) Personalized Medicine in Healthcare Systems: Legal, Medical and Economic Implications. Springer, Berlin. https://doi.org/10.1007/978-3-030-16465-2

[2] Sindeeva, L.V. and Rudnev, S.G. (2017) Hit-Carter Somatotype Age-and-Sex Variability in Adults and the Possibility of Its Bioimpedance Assessment (by the Example of the Russian Population of Eastern Siberia). Morphology, 151, 77-87. (In Russian)

[3] Cespendes, F.E.M., Kwan, M.L., Kushi, L.H., Weltzien, E.K., Castillo, A.L., Caan, 
B.J., Chen, W.Y., Sweeney, C. and Bernard, P.S. (2017) Body Mass Index, pam50 Subtype, Recurrence, and Survival among Patients with Nonmetastatic Breast Cancer. Cancer, 123, 2535-2542. https://doi.org/10.1002/cncr.30637

[4] Lopes, V.P., Cossio-Bolanos, M., de Arruda, M., Gomez-Campos, R., Hespanhoi, J.E. and Rodriges, L.P. (2017) Linear and Nonlinear Relationships between Body Mass Index and Physical Fitness in Brazilian Children Breast Cancer. American Journal of Human Biology, 29, 23-235. https://doi.org/10.1002/ajhb.23035

[5] Liu, J.X., Liu, J.H., Boghossian, N.S., Cai, B., Hazlett, L.J. and Frongillo, E.A. (2017) Body Mass Index Trajectories during Infancy and Pediatric Obesity at 6 Years. Annals of Epidemiology, 27, 708-715. https://doi.org/10.1016/j.annepidem.2017.10.008

[6] Habib, S.R., Alghofaily, S., Althammad, A., Alshamrani, H. and Awan, K.H. (2017) Relationship of Body Mass Index with Diet, Physical Activities, and Lifestyles of Dental Students. Journal of Contemporary Dental Practice, 18, 899-904.

https://doi.org/10.5005/jp-journals-10024-2146

[7] Samotesov, P.A., Russian, A.N., Shaboha, A.D., Kasimov, V.I. and Kirichenko, A.A. (2018) The Constitutional Features of the Histological Structure of the Menisci of the Knee Joint. Journal of Anatomy and Histopathology, 7, 110-114. (In Russian) https://doi.org/10.18499/2225-7357-2018-7-2-76-84

[8] Park, H.W., Kim, K.H., Song, I.G., Kwon, T.G. and Bae, J.H. (2017) Body Mass Index, Carotid Plaque, and Clinical Outcomes in Patients with Coronary Artery Disease. Coronary Artery Disease, 28, 278-286. https://doi.org/10.1097/MCA.0000000000000467

[9] Gutierrez-Bedmar, M., Garcia-Rodriguez, A., Munoz-Bravo, C., Marizscal, A. and Martinez, E. (2015) Psychiatric Status across Body Mass Index in a Mediterranen Spanish Population. PLoS ONE, 10, e0145414. https://doi.org/10.1371/journal.pone.0145414

[10] Fang, C. and Liang, Y. (2017) Social Disparities in Body Mass Index (BMI) Trajectories among Chinese Adults in 1999-2011. International Journal for Equity in Health, 16, 146. https://doi.org/10.1186/s12939-017-0636-5

[11] Zorina, E.V., Petrova, M.M., Kaskaeva, D.S., Mudrova, L.A., Danilova, L.K. and Krylova, E.Y. (2015) The Relationship of the Component Composition of the Body and the Ability to Predict the Magnitude of Changes in Blood Pressure in Men with Arterial Hypertension. Scientific Review, 5, 60-65. (In Russian)

[12] Barba, M., Pizzuti, L., Sergi, D., Di lauro, L., Izzo, F., Rinaldi, M., Maugeri-Sacca, M., Vici, P., Sperduti, I., Natoli, C., Iezzi, L., Grassadonia, A., Gamucci, T., Mentuccia, L., Vaccaro, A., Moscetti, L., Michelotti, A., Landucci, E., Perracchio, L. and Pescarmona, E. (2016) Body Mass Index and Treatment Outcomes in Metastatic Breast Cancer Patients Treated with Eribulin. Journal of Cellular Physiology, 231, 986-991. https://doi.org/10.1002/jcp.25213

[13] Pereira, D., Severo, M., Ramos, E., Lucas, R., Barros, H., Branco, J., Santos, R.A. and Costa, L. (2017) Potential Role of Age, Sex, Body Mass Index and Pain to Identify Patients with Knee Osteoarthritis. International Journal of Rheumatic Disease, 20, 190-198. https://doi.org/10.1111/1756-185X.12611

[14] Nuttall, F.Q. (2015) Body Mass Index. Nutrition Today, 50, 117-128. https://doi.org/10.1097/NT.0000000000000092

[15] González, J.E. (2013) Body Composition: Assessment and Clinical Value. Endocrinología y Nutrición, 60, 69-75. https://doi.org/10.1016/j.endoen.2012.04.015

[16] Merrill, Z., Chambers, A. and Cham, R. (2017) Impact of Age and Body Mass Index on Anthropometry in Working Adults. Proceedings of the Human Factors and Er- 
gonomics Society Annual Meeting, 61, 1341-1345. https://doi.org/10.1177/1541931213601818

[17] Madden, A.M. and Smith, S. (2016) Body Composition and Morphological Assessment of Nutritional Status in Adults: A Review of Anthropometric Variables. Journal of Human Nutrition and Dietetics, 29, 7-25. https://doi.org/10.1111/jhn.12278

[18] Dratva, J., Bertelsen, R., Janson, C., Johannessen, A., Benediktsdóttir, B., Bråbäck, L. and Real, F. (2016) Validation of Self-Reported Figural Drawing Scales against Anthropometric Measurements in Adults. Public Health Nutrition, 19, 1944-1951. https://doi.org/10.1017/S136898001600015X

[19] Galkina, T.N. and Kalmin, O.V. (2017) Characteristics of Physique and Dermatoglyphics of Penza Boys and Girls. News of Higher Educational Institutions. Volga Region. Medical Sciences, 2, 31-41. (In Russian)

[20] Pivotrak, K.V. (2017) Anthropometric Studies of Patients with Nonalcoholic Fatty Liver Disease. Zaporozh Medical Journal, 5, 623-628.

https://doi.org/10.14739/2310-1210.2017.5.110169

[21] Gutnik, B., Zuoza, A., Zuozienė, I., Alekrinskis, A., Nash, D. and Scherbina, S. (2015) Body Physique and Dominant Somatotype in Elite and Low-Profile Athletes with Different Specializations. Medicina, 51, 247-252. https://doi.org/10.1016/j.medici.2015.07.003

[22] Huang, S.-W., Hsieh, F.-C., Lin, L.-F., Liao, C.-D., Ku, J.-W., Hsiao, D.-J. and Liou, T.-H. (2018) Correlation between Body Composition and Physical Performance in Aged People. International Journal of Gerontology, 12, 186-190. https://doi.org/10.1016/j.ijge.2018.02.011

[23] Martín-Matillas, M., Valadés, D., Hernández-Hernández, E., Olea-Serrano, F., Sjöström, E., Delgado-Fernández, M. and Ortega, F.B. (2014) Anthropometric, Body Composition and Somatotype Characteristics of Elite Female Volleyball Players from the Highest Spanish League, Journal of Sports Sciences, 32, 137-148. https://doi.org/10.1080/02640414.2013.809472

[24] Kaur, B., Kaur, S., Singh, S.P., Sidhu, L.S. and Kaur, R. (2001) Secular Trends in Somatotypes among Female University Students. The Anthropologist, 3, 257-260. https://doi.org/10.1080/09720073.2001.11890723

[25] Schaffer, W.C. (2016) Total Body Mass Estimation from Anthropometric Measurements in Modern Young Adult U.S. Populations with Healthy Body Fat Percentages (NHANES III). Journal of Forensic Sciences, 61, 1431-1439. https://doi.org/10.1111/1556-4029.13145

[26] Gallagher, D., Shaheen, I. and Zafar, K. (2008) State-of-the-Art Measurements in Human Body Composition: A Moving Frontier of Clinical Importance. International Journal of Body Composition Research, 6, 141-148.

[27] Pomeroy, E., Macintosh, A., Wells, J.C.K., Cole, T.J. and Stock, J.T. (2018) Relationship between Body Mass, Lean Mass, Fat Mass, and Limb Bone Cross-Sectional Geometry: Implications for Estimating Body Mass and Physique from the Skeleton. American Journal of Physical Anthropology, 166, 56-69. https://doi.org/10.1002/ajpa.23398

[28] Borkan, G.A., Hults, D.E. and Mayer, P.J. (1982) Physical Anthropological Approaches to Aging. American Journal of Physical Anthropology, 25, 181-202. https://doi.org/10.1002/ajpa.1330250511

[29] Starchik, D.A. and Nikityuk, D.B. (2015) Features of the Body Mass Index in Women of Different Somatotypes. Morphological Statements, 4, 21-24. (In Russian)

[30] Kolokoltsev, M.M. and Nosov, A.V. (2018) Characterization of Anthropometric In- 
dicators of Students with Different Levels of Physical Health. NovaInfo.Ru, 1, 151-155. (In Russian)

[31] Mirrakhimov, A.E., Lunegova, O.S., Kerimkulova, A.S., Moldokeeva, C.B., Nabiev, M.P. and Mirrakhimov, E.M. (2012) Cut Off Values for Abdominal Obesity as a Criterion of Metabolic Syndrome in an Ethnic Kyrgyz Population (Central Asian Region). Cardiovascular Diabetology, 11, 1-6.

https://doi.org/10.1186/1475-2840-11-16

[32] Kerimkulova, A.S., Luegova, O.S., Mirrahimov, A.E., Alibaeva, N.T., Neronova, K.V., Bayramukova, A.A. and Mirrahimov, E.M. (2014) The Association of Leptin with Obesity and Arterial Hypertension in the Ethnic Kyrgyz Group. Therapeutic Archive, 86, 49-53. (In Russian)

[33] Balinova, N.V. and Khomyakova, I.A. (2015) Anthropology Sart-Kalmakov of Kyrgyzstan. Bulletin of the Kalmyk Institute for Humanitarian Studies of the Academy of Sciences, 1, 60-65. (In Russian)

https://doi.org/10.22162/2075-7794-2015-19-1-60-65

[34] Kontsevaya, A.V., Myrzamatova, A.O., Polupano, A.G., Alikhanova, K.A., Kashirin, A.K., Halmatov, A.N., Altymysheva, A.T., Ikakov, E.B., Balanova, Y.A. and Dzhumagulova, A.S. (2017) Ethnic Features of the Prevalence of Major Cardiovascular Risk Factors among Rural Residents in the Russian Region and the Regions of Kyrgyzstan and Kazakhstan. Russian Journal of Cardiology, 6, 113-121. (In Russian) https://doi.org/10.15829/1560-4071-2017-6-113-121

[35] Sakibaev, K.Sh., Alekseeva, N.T., Nikityuk, D.B., Tashmatova, N.M. and Klochkova, S.V. (2018) Anthropometric Features of Ethnic Kyrgyz of Different Age Groups. Zhurnal Anatomii i Gistopatologii, 7, 56-60. (In Russian) https://doi.org/10.18499/2225-7357-2018-7-4-56-60

[36] Mazidi, M., Banach, M. and Kengne, A.P. (2018) Lipid and Blood Pressure Meta-Analysis Collaboration Group. Prevalence of Childhood and Adolescent Overweight and Obesity in Asian Countries: A Systematic Review and Meta-Analysis. Archives of Medical Science, 14, 1185-1203. https://doi.org/10.5114/aoms.2018.79001

[37] Nikityuk, B.A. and Chtetsov, V.P. (1983) Human Morphology. Moscow University Publishing House, Moscow, $344 \mathrm{p}$.

[38] Borges, C., Fernandes, L.F. and Bertoncello, D. (2013) Relationship between Lumbar Changes and Modifications in the Plantar Arch in Women with Low Back Pain. Acta Ortopedica Brasileira, 21, 135-138.

https://doi.org/10.1590/S1413-78522013000300001 